TP Periodica Polytechnica

Social and Management

Sciences

24(2), pp. 96-101, 2016

DOI: $10.3311 /$ PPso. 8715

Creative Commons Attribution (i)

RESEARCH ARTICLE

\section{Consumer Neuroscience in Practice: The Impact of Store Atmosphere on Consumer Behavior}

\author{
Jakub Berčík $^{1 *}$, Elena Horská ${ }^{1}$, Jana Gálová1 ${ }^{1}$ Eko Sri Margianti ${ }^{2}$
}

Received 29 October 2015; accepted 18 December 2015

\begin{abstract}
Consumer neuroscience is a phenomenon that has become an important tool of marketing management when defining customer driven strategies. The aim of consumer neuroscience (neuromarketing research) is a better understanding of the principles of decision-making and the strategy of customer and consumer behavior in economic processes through neuroimaging and biometric methods, psychological and neurobiological concepts and knowledge. The scientific discipline consumer neuroscience (neuromarketing) might be defined as a new direction of interdisciplinary research that engages in the research of neurobiological correlates and mechanisms applicable in business and economic decision-making, selection, strategy and planning. The paper deals with an interdisciplinary survey of the impact of music on the emotional response and merchandising of goods on customer perception when selecting food (wine). Using neuroimaging and biometric methods we have identified the impact of these incentives on customer perception, based on which we have established specific recommendations utilizable in practice in order to improve selling strategies, sales culture, and ultimately maximize profits.
\end{abstract}

\section{Keywords}

consumer neuroscience, emotions, consumer behavior, store atmosphere

\footnotetext{
${ }^{1}$ Faculty of Economics and Management, Slovak University of Agriculture in Nitra, Tr. Andreja Hlinku 2, 94976 Nitra, Slovakia

${ }^{2}$ Gunadarma University, J1. Margonda Raya 100, Depok, West Java 16424, Indonesia

*Corresponding author, e-mail: bercik.jakubxx@gmail.com
}

\section{Introduction}

In the process of the adjustment of the retail environment, formed by important components which influence consumers, perception plays a significant role supported by all five sensory organs. A prerequisite of adequate buying behavior is the detection of customer senses perception and an adaptation of visual merchandising in the retail environment. Consumers when buying products seek to meet their own needs, which companies are trying to follow up with creating proper conditions in the sales area. Among the features needed first to attract attention and then to select a product, is the position of the product on the shelf, the impact of music, colors, lighting and scents that directly affect the consumer emotions. Natural perception of music causes emotional response in humans, resulting from stimulations transmitted to the central nervous system. These perceptions influence consumer behavior to varying degree, as individuals evaluate heard musical formula from their subjective point of view. Among the standard marketing research methods also new methods are coming to the fore, aimed at monitoring neurological and biometric data, as are consumer neuroscience or neuromarketing. Conscious customer perception is important, but mostly it does not reflect real behavior. Given this fact, companies are increasingly applying neuroimaging and biometric techniques to survey the unconscious components of consumer perception. They help to uncover hidden customer reactions and identify relations between internal emotions and external consumer manifestation and buying behavior. Detailed mapping of consumer behavior and responses gains importance in recent years as a result of global economic problems and financial recession, when consumers reassess the volume and financial costs of their purchases more than ever.

\section{Methodology}

Consumer behavior in the sales environment is influenced by several factors simultaneously, these include the elements of visual merchandising affecting sensory senses of consumers. The main aim of this paper is to survey the impact of music and merchandising of goods on consumer emotions and perception. 
The research paper is based on the study of current knowledge in the following areas:

- Consumer neuroscience (neuromarketing), neuroeconomics;

- Sensory marketing and aroma marketing;

- Visual merchandising.

For conducting the research we selected a relatively new company "Pivnica pod hradom" (Cellar under the castle) in the center of the city Nitra). The testing was carried out in April 2015, while the sample consisted of 11 respondents of different age category, both sexes and various educational levels in order to provably compare their emotional reactions. The neuromarketing research method was selected for surveying the impact of music on the emotional component of customers, which was applied to the respondents in laboratory conditions (see Fig. 1).

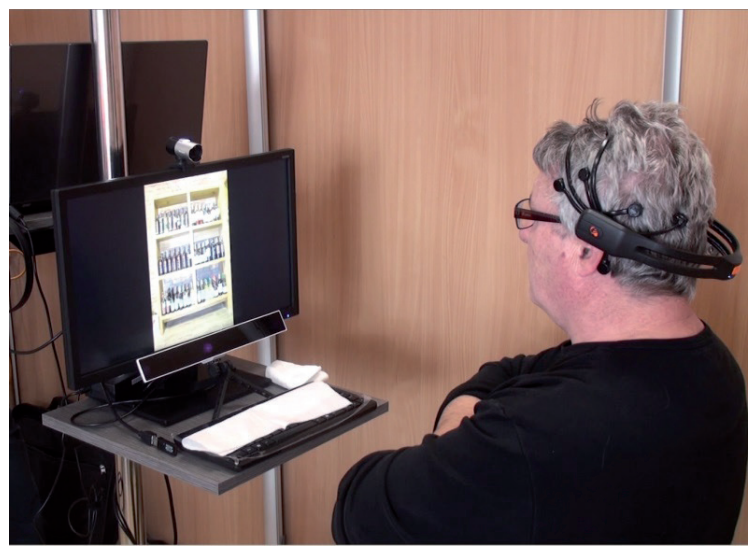

Fig. 1 Testing in laboratory conditions Source: Own documentation of authors 2015

Firstly, we created short videos (stimulus) in the sales environment of the wine shop (wine distribution on the shelves) comprising the visual arrangement of wines. We have inserted a music into the video (slow French versus fast Slovak) in order to compare them with the sample without music. Respondents focused their attention on these modified audiovisual videos in order to determine their preferences and emotions. We surveyed the emotional state of respondents in laboratory conditions with a mobile device Emotive EPOC headset (Fig. 2), which measures electrical brain activity. The Affective Suite software tool detected changes in the emotions of respondents in real time, thus providing information about the emotional state of respondents while viewing the stimulus.

The particular types of emotions recorded by the software were immediate engagement, frustration, meditation and excitement. Eye movements (Fig. 3) were monitored by fixed binocular Eye Tracker from the company Gazepoint. The recorded data about eye movements were exported to Gazepoint Analysis software, where it was possible to observe points to which respondents focused their vision cumulatively with a statistical tool called heat maps.

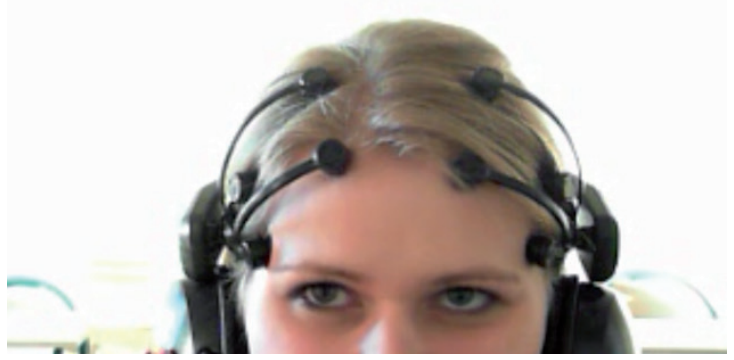

Fig. 2 EEG testing of stimulus from the sales environment Source: Own documentation of authors 2015

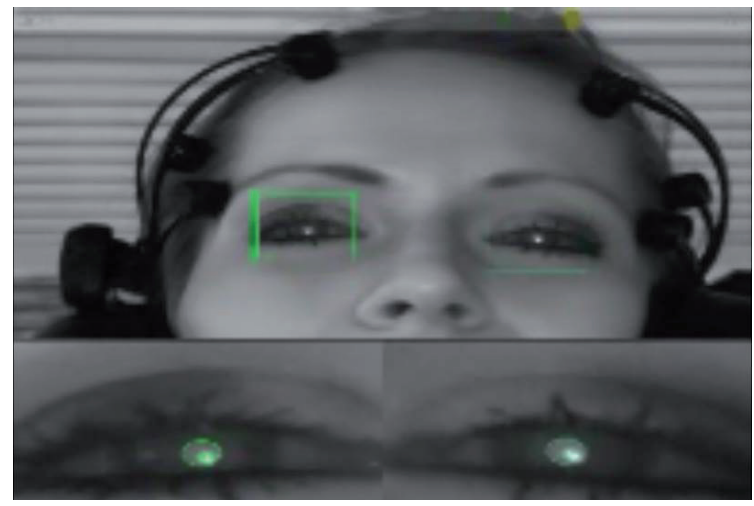

Fig. 3 Monitoring eye movements Source: Own documentation of authors 2015

The study results in defining the relations between different fields and the possibility of using interdisciplinary knowledge to increase the information value of consumer studies and their use for creating marketing strategies.

\section{Theoretical Background}

Consumer behavior is explained by Solomon et al. (2006) as the process where individuals select, purchase, use and deprive goods, services, ideas or experiences to fulfill their needs and desires. Smith (2001) considers perception as a way how someone explains a stimulus, which might be advertising, packaging, advertising message, stores, uniforms etc. The human perception system tends to organize, modify and twist all input data. Perception is just selective because it sees what it wants to see. The connection can be found in the definition of Schiffman and Kanuk (1991), who described the perception as a process where the individual selects, organizes and interprets stimuli into a meaningful and continuous image. Merchandising is further specified by Tellis (2000) as the placement of a product within viewing angle of those passing by. The main objective of merchandising is the display of goods within the store space. According to Morgan (2011) the task of the visual merchandiser is mainly the increase in sales by enticing customers to the store using a showcase or special display of goods. Music affects the humans with all its dimensions (Mátejová, 1980). Music is the component that inherently belongs to visual merchandising forms. According to Franek (2007) inappropriately 
chosen background music can send a signal to the customer that he found himself in a place where he does belong. Boček et al. (2009) emphasize that when hearing faster music customers move through the store faster, therefore the type of music might also affect product selection.

If we consider the enrichment of basic approaches to examining the consumer and creating customer-driven strategies, we need to realize in which areas we can apply technological advances and in what direction. Lindstrom (2009) points out that today, thanks to advanced new tools and technologies that businesses have available and current research in the field of consumer behavior, cognitive psychology and neuroscience, companies are aware of what affects customers much more than we can imagine.

The concept of applying neuroscience methods into research of consumer emotions and cognitive reactions has caused massive interest recently. Indeed, the usage of psychophysiological techniques in consumer research is not really new considering that monitoring pupils dilatation and electrodermal activity were observed already in 1960, followed later by eye tracking and measurement of heart activity (Wang and Minor, 2008). The term "neuromarketing" was first used in 2002 by professor Ale Smidt and is more related to the practical usage of neuroscience knowledge for managerial purposes (Hubert and Kenning, 2008), while the identical term "consumer neuroscience" is considered more appropriate in the academic field (Hubert, 2010; Ramsøy, 2014).

As written by Hill and Simon (2010), all human beings use 3 part brain: visual, emotional and rational. This gives the answer to differences between emotional versus verbal response of customers/respondents in many research action situations. Such limitations of traditional research can be overcome by using new research techniques from the field of neuromarketing or consumer neuroscience:

- Facial Coding measures how people feel. The human face registers a wide variety of emotional states. Facial expressions can be read at the level of observable changes (e.g. while eating, drinking, testing some food samples) and at the level of unobservable micro-muscle changes (positive or negative emotional responses).

- Eye Tracking measures what people see. It has wide variety of uses in neuromarketing as it provides valuable indications of interest, attention and attraction.

- Electroencephalography (EEG) accounts the most popular neuromarketing technology because of its relatively low costs and manageable equipment requirements (Genco et al., 2013). It can measure moment-to-moment changes and identify memory activation in real time.

- Functional magnetic resonance imaging is considered as the best standard method for neuroscientists, but at the same time as the least practical. In consumer neuroscience (the academic neighbouring discipline to neuromarketing), functional magnetic resonance imaging has been used to study branding, advertising, shopping and entertainment.

\section{Results and Discussion}

We have decided to use two different music styles, which we considered the most suitable to create the necessary atmosphere in the wine shop. The first stimulus was an option without music, in order to adequately compare the auditory perception of consumers. As the first stimulus with music a fast type of Slovak music was selected, since choosing Slovak music might tend to increase sales of wines from Slovak regions. As the tempo of the music was relatively fast, it could have induced faster movement of the customer through the store and therefore an impulsive purchase within the Slovak assortment of wines. The complete opposite was the other style, which was slow paced and French origin, as the wine shop offers also foreign wines. Under the influence of the slow tempo of music and lower intensity of sound level it was expected that customers would stay longer in the store, causing more precise selection among the products, eventually an increase in the estimated purchase.

\subsection{Testing stimulus in the sales environment with Slovak music}

The evaluation of emotions was carried out by dividing the measured ten second periods into five intervals (two seconds apart), which is sufficient time for a change in surveyed emotions (emotional engagement, excitement) of respondents to tested stimulus. The first surveyed emotion was engagement, shown in Fig. 4. From the measured average values of engagement a slight bias towards Slovak music was observed when buying wine. Engagement increases over time, which may indicate increased interest in listening to Slovak music in the store. This type of music can be considered suitable for reproduction in a wine shop. In some cases, it might also bring forward patriarchality when selecting wine, which means that if customers hear Slovak music played, their purchase is likely to be directed towards Slovak wine brands.

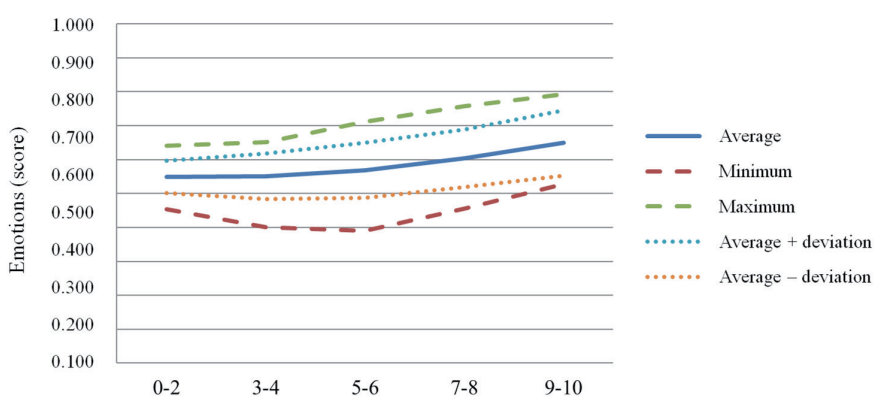

Fig. 4 Engagement while monitoring stimulus with Slovak music Source: Own documentation of authors 2015 
In the case of excitement, in the second and third period (Fig. 5) we observed an increase in the average level of this emotion, which may be caused by the fact that some respondents were more biased under the influence of Slovak music as it is also reflected in the variance of values during this period. As the excitement speaks volumes about the level of sensitivity to sensory stimuli, it can be concluded that the effect of Slovak music caused some moderate level of sensitivity, which can be essential in implementing Slovak music production to music playlists in retail stores. In practice such background music can be effective not only in increasing the perception sensitivity of the in-store stimuli but also in motivating customers to purchase Slovak products.

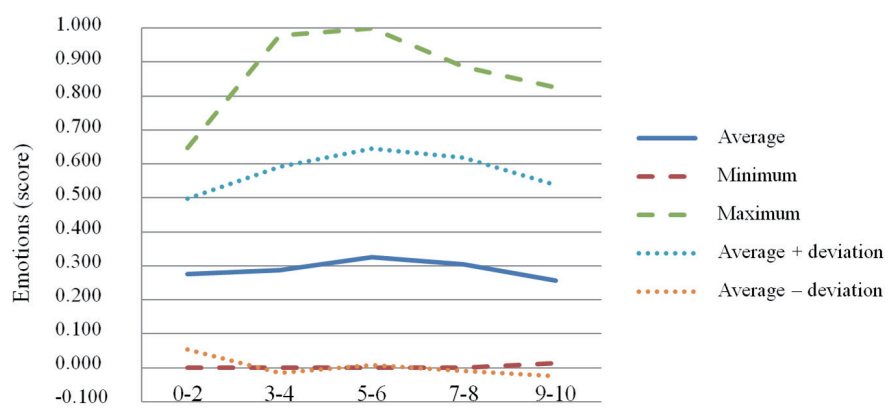

Fig. 5 Excitement while monitoring stimulus with Slovak music Source: Own documentation of authors 2015

The impact of music on humans is different in terms of life cycle stages of human evolution, gender and other related categories. The selection from the viewpoint of gender is clarified because of the product portfolio of wine products. Females showed high fluctuations in response sensitivity to the stimuli, while males do not reported such high sensitivity. Gender comparison showed greater engagement of women compared to men when listening to Slovak music, which might be related to the fact that women are more emotional than men.

\subsection{Testing stimulus in the sales environment with French music}

Wines are inherently connected with French or Italian foreign rhythms as these are countries with numerous wine regions. We assigned the slow and serene style to a French melody, sounding calm and reassuring, which evoked a sense of romance, warm atmosphere, good and soothing mood respondents when listening to it. Also in this case emotional engagement and excitement were measured through the EEG device. The highest average engagement rate was achieved at the beginning and in the end of sensing the stimulus with background music. Thus we can conclude that the respondents can be affected by music in just a few seconds. The overall average emotional engagement amounted to approximately 0.6 (score), as seen in Fig. 6, which means relatively low boredom of respondents under the influence of this stimulus.

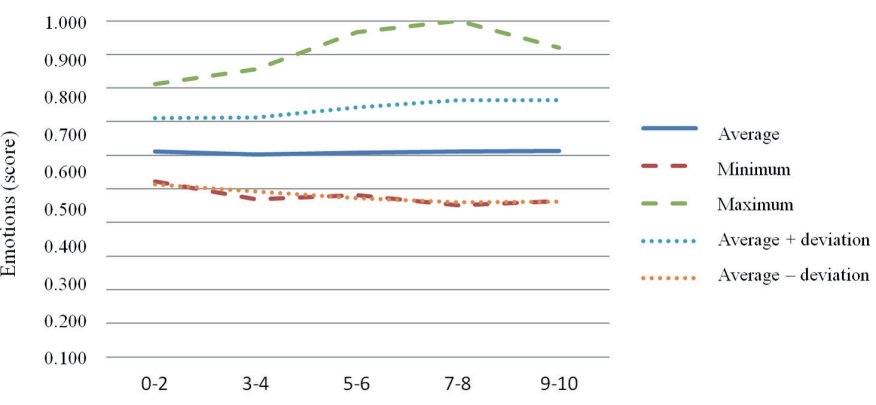

Fig. 6 Engagement while monitoring stimulus with French music Source: Own documentation of authors 2015

Engagement presumes high attentiveness and concentration and is reflected in the French music more than in the Slovak. It can be caused by a calm rhythm that leaves the respondent in his natural perception of his surroundings. If customers feel comfortable and satisfied, they can spend more time in the store, which even projects greater choice from products for final consumption. From the viewpoint of managers it is important to make customers feel comfortable in the company so that they shall purchase just in the particular store and in larger quantities.

Some respondents responded more to this initiative in the second interval, which is reflected in the maximum levels of excitement, see Fig. 7.

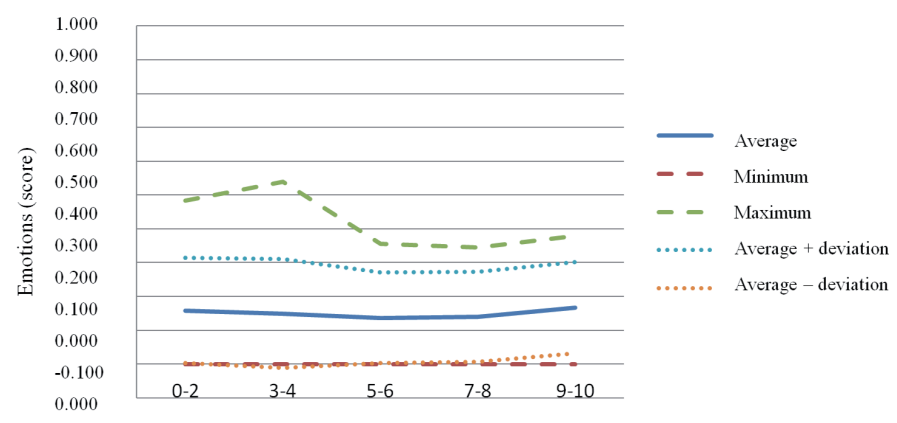

Fig. 7 Excitement while monitoring stimulus with French music Source: Own documentation of authors 2015

\subsection{Testing stimulus in the sales environment without music}

Humans cannot naturally perceive silence, because everywhere it is accompanied by different sounds and melodies. The intensity of the sound level can be sensed from above $20 \mathrm{~dB}$, so we begin to hear sounds similar to the humming of tree leaves. We surveyed whether respondents prefer quiet sales stores and feel better there. In order to detect any differences in the subconscious perception of stimuli without background music we carried out measurement of electrical brain activity.

Overall lower average values of engagement compared to testing stimuli complemented with music on the level 0.5 (score), see. Fig. 8, show less interest in the stimulus without 
music. The course of viewing wine products is not disrupted by any influence during the monitored time period and therefore average values are approximately similar. The mentioned assumption is confirmed by subconscious emotions, and therefore results in a detectable impact of the influence of music in the company. Confirming the low bias without the use of music compared to Slovak and French music supports the statement that the store has a friendly atmosphere when there is music played in the background. From the perspective of the stores it is a positive information, because in most of them music is played not only to create a pleasant atmosphere for customers, but also takes into account the comfort of employees.

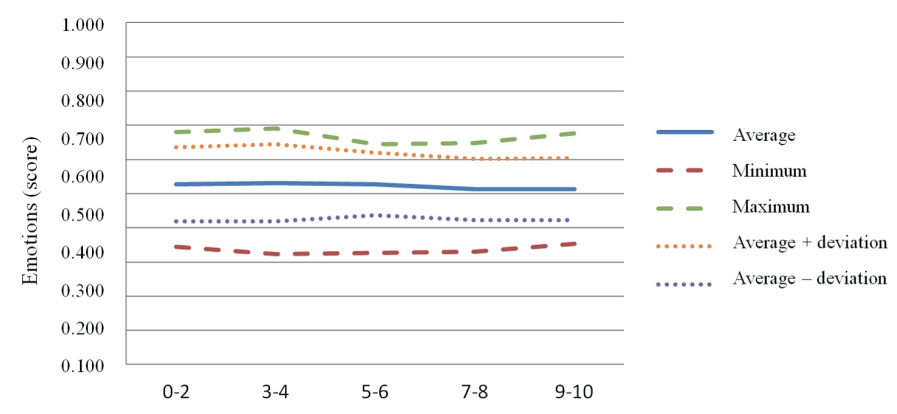

Fig. 8 Engagement while monitoring stimulus without music Source: Own documentation of authors 2015

The emotion excitement gradually declines over the monitored time, see Fig. 9. In contrast to the stimuli of the sales environment complemented with music a decrease of excitement can be observed from the first period, which might be associated with the realization that the presentation of products takes place without any music. Again, we can conclude that it is a detectable impact of music on the customer in the store.

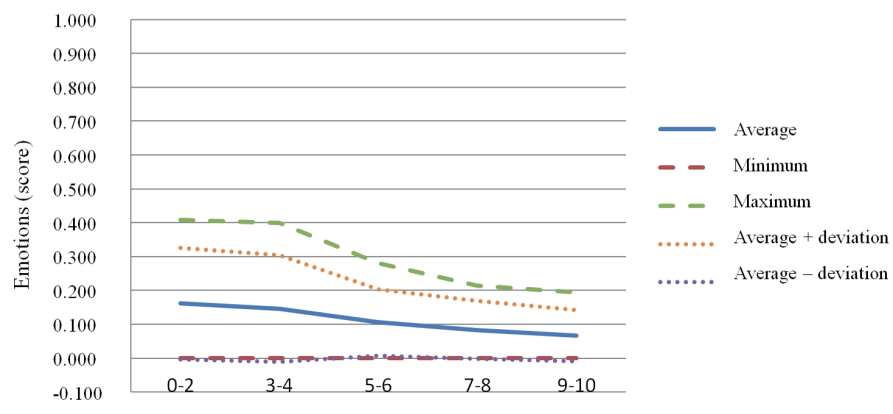

Fig. 9 Excitement while monitoring stimulus without music Source: Own documentation of authors 2015

\subsection{Testing the stimulus in the sales environment with a full vs. half-empty rack}

In this case we also used the video stimulus without music in order to survey whether a filled rack or an almost empty (1 bottle of wine) attracts more attention. We used the biometrics method Eye tracker, where based on the resulting heat map, as seen in Fig. 10, the initial sight of respondents pointed to the only bottle in the half-empty rack (red), and then the majority of respondents (greater concentration of the heat map) were attracted by a fully arranged rack, which means that the image of filled racks with products is more engaging than half empty racks. Half-empty shelf is conceived as a rack with one to three bottles. It can also give the stimuli to refrain longer at packed racks, where products are placed next to each other and therefore this attention tends to lead to buying the product. The prerequisite here is that the customer when moving in the store stops at the rack in which the products are placed next to each other and there are no empty spaces between them.

Later, the sight of the respondents moved back from the full rack to the side rack with one bottle of wine. On the full shelf we observed bias for the labels on the bottles, heat points were concentrated on the bottle placed in the middle with a pale label. Wines in dark bottles with overall darker design do not attract the attention of customers the way the significantly paler ones from other wines. Therefore, if the bottle is standing separately on a shelf, it catches the whole primary attention of customers compared to the situation if it is positioned among other products. This interesting result leads to the display of an exclusive bottle of wine, which can be supported by related decorative elements to attract the attention of customers.

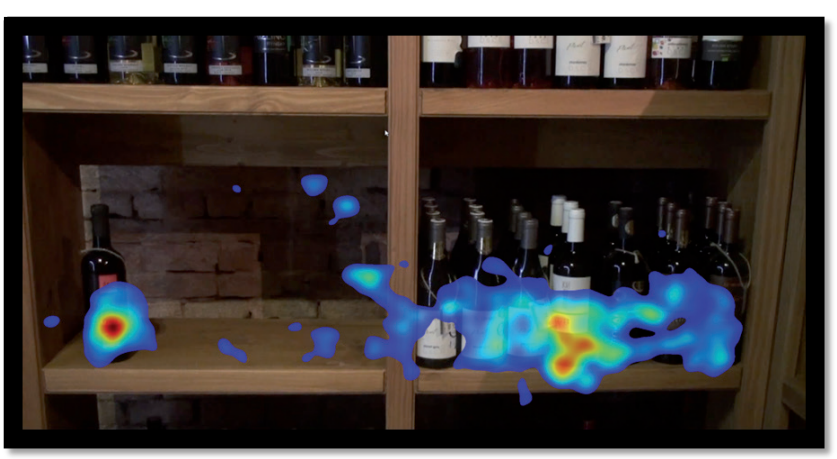

Fig. 10 Heat map - testing full vs. half-empty rack Source: Own documentation of authors 2015

\section{Conclusion}

In the retail store, based on the type of merchandised goods it is necessary to adjust the music (genre, style, tempo and quality of music played) to create a pleasant atmosphere. We therefore observed changes in the emotional behavior of consumers under the influence of music as an essential component of visual merchandising.

This paper aimed to present results based on data gathered from innovative neuroimaging technique using an electroencephalograph and biometric method with eye camera in laboratory conditions, based on subconscious reactions of consumer behavior influenced by music. Based on EEG measurements the highest average values of emotional engagement were calculated for the French music in the middle of the monitored time period. Thus we can conclude that the respondents are 
influenced by the melody within a few seconds. In the case of excitement (sensitivity to sensory stimuli) the highest average values were recorded for the stimuli with Slovak music. On the contrary, the lowest sensitivity of perception was recorded when testing the stimulus of sales environment without using music. Hereby we have confirmed the assumption associated with the subconscious emotions, which means there is a detectable impact of music on customer emotions during making the purchase. Silence for the customers in the store is unattractive, therefore we can consider the assumption of visiting primarily stores where music is played to have been confirmed.

By testing the merchandising of products on the shelves, based on the resulting heat map we found that primary attention was given to a bottle separated alone in the rack. The sight of respondents was focused on the almost empty shelf, which contained a single piece of product. This interesting result leads to merchandising the product separately, giving the impression that it is an exceptional noteworthy product.

\section{Acknowledgement}

This article is part of the research project VEGA 1/0874/14 "The use of neuromarketing in visual food merchandising" conducted at the Department of Marketing and Trade at the Faculty of Economics and Management of the Slovak University of Agriculture in Nitra, Slovakia.

\section{References}

Boček, M., Jesenský, D., Krofiánová, D. (2009) POP - In-store komunikace v praxi: trendy a nástroje marketingu v mistě prodeje. (POP - In-store Communication in Practice: Trends and Tools of Marketing at the Point of Purchase.) Grada, Praha. (in Czech)

Franék, M. (2007) Hudebni psychologie. (Psychology of Music.) Karolinum, Praha. (in Czech)

Genco, S. J., Pohlmann, A. P., Steidl, P. (2013) Neuromarketing for Dummies. John Wiley \& Sons, Mississauga.

Hill, D., Simon, S. (2010) Emotionomics: Leveraging Emotions for Business Success. 3. Kogan Page, London.

Hubert, M. (2010) Does neuroeconomics give new impetus to economic and consumer research? Journal of Economic Psychology. 31(5), pp. 812817. DOI: 10.1016/j.joep.2010.03.009

Hubert, M., Kenning, P. (2008). A current overview of consumer neuroscience. Journal of Consumer Behaviour. 7(4-5), pp. 272-292. DOI: $10.1002 / \mathrm{cb} .251$

Lindstrom, M. (2009) Nákupologie. (Buyology.) Computer Press, Brno. (in Czech)

Mátejová, Z., Mašura, S. (1980) Muzikoterapia pri jazykovosti. (Music Therapy in Language Use.) SPN, Bratislava. (in Slovak)

McLellan, L. (2014) 5 predictions for marketing in 2016. [Online] Available from: http://blogs.gartner.com/laura-mclellan/5-predictions-marketing-2016/ [Accessed: 26th April 2015]

Morgan, T. (2011) Visual merchandising: Window and in-store displays for detail. Laurence King, London.
Nagyová, L', Horská, E., Kretter, A., Kubicová, L', Košičiarová, I., Récky, R., Berčík, J., Holienčinová, M. (2014) Marketing. SPU VES, Nitra.

Ramsøy, Z. T. (2014) Neuromarketing \& Consumer Neuroscience. Neurons Inc ApS.

Schiffman, L. G., Kanuk, L. L. (1991). Consumer Behavior. Prentice-Hall, London.

Smith, P. (2001) Marketing Communications. Kogan Page, London.

Solomon, M. R., Marshall, G. W., Stuart, E. W. (2006) Marketing: Očima světových marketing manažerů. (Marketing: Real People, Real Choices.) Computer Press, Brno. (in Czech)

Tellis, G. J. (2000) Reklama a podpora prodeje. (Advertising and Sales Promotion.) Grada, Praha. (in Czech)

Wang, Y. J., Minor, M. S. (2008) Validity, reliability, and applicability of psychophysiological techniques in marketing research. Psychology and Marketing. 25(2), pp. 197-232. DOI: 10.1002/mar.20206 